\title{
Modelling the development of drilling operations in iron ore quarries (based on Kachkanar MPP)
}

\author{
Andrey Regotunov ${ }^{1 *}$ and Vladimir Antonov ${ }^{1}$ \\ ${ }^{1}$ Institute of Mining, Ural Branch of the Russian Academy of Sciences, Ekaterinburg, Russia
}

\begin{abstract}
The necessity of application of quantitative models of drilling operations development in iron ore quarries for the justified planning of drilling volumes and the relevant fleet of drilling rigs has been shown. For this purpose, experimental regression studies of the patterns of formation and development of drilling operations in the transition period of the modern market economy have been carried out using the example of the Kachkanar Mining and Processing Plant, which has typical characteristic features and dynamics of changes in mining production in Russia. Based on the analysis of the annual technical and economic indices of Kachkanar MPP, conclusions have been drawn about the characteristics of the depression period of drilling production in the 1990s and its subsequent growth, coupled with qualitative changes in the fleet of drilling rigs and productivity thereof. In order to establish the relevant quantitative relationships and development forecasts of the drilling operations at the plant, a nonlinear regression model for the distribution of the length of wells drilled per year has been created, depending on the calendar time, the number of drilling rigs and their utilization factor. The model has a high determination factor of 0.9. It is adequate to the errors of the initial indices, it is statistically reliable, and in this confidence interval, it expresses regularities in changes in the annual length of the drilled wells. According to the regularities, interpretation of transient processes and forecast estimates of the development of drilling operations have been provided. Key words: forecast, extraction, ore, drilling operations, drilling rigs, indices, length of wells, regression, model.
\end{abstract}

\section{Introduction}

Forecasting and planning of drilling volumes and an associated fleet of drilling rigs is directly determined by the state of mining in Russia. Over the past 35-40 years, it has changed significantly due to the transition of industrial infrastructure and management to a market economy. The moderate increase in production volumes that began in the 1980s since the early 1990s had severely disrupted. The crisis in metallurgy in 1993-2000 had led the iron ore industry in Russia to the same uncertainty. In paper [1] transitional periods of

\footnotetext{
* Corresponding author: pochta8400@inbox.ru
} 
decline in volumes of mining production (1991-1994), unstable stabilization (1995-1998) and, since 1999, - relative growth are noted.

To predict drilling operations in iron ore quarries and management thereof, it is necessary to disclose and understand the patterns of their formation and development to the stage of modern manning and use of drilling rigs. In [2-4], devoted to this problem, the optimization of technological operations of mining production has been considered, and in the studies [5-10] a technique has been proposed and the results of calculation of the optimal number of drilling rigs in quarries have been presented. The results of the minimization of costs for drilling operations have also been stated. However, these studies and conclusions are fragmentary and do not give any idea of these regularities.

In this article, the results of the corresponding experimental regression studies are presented, which make up the shortcomings noted. They are based on the data of annual technical and economic indices of mining enterprises, in which the dynamics of drilling operations have the characteristic features typical for the transition period.

\section{Analysis of annual drilling performance at Kachkanar MPP}

EVRAZ KGOK "Kachkanar MPP", OJSC, located in the Urals, has been among the iron ore enterprises that have the most characteristic drilling performance dynamics. According to the collection "Technical and Economic Indices of Mining Enterprises" [12], periodically published by the Institute of Mining of the Ural Branch of the Russian Academy of Sciences, the following annual drilling parameters have been sampled at this plant: $L$-the length of drilled wells per year (drilling volume), $K$ - calendar time rig use factor, $n-$ average number of rigs.

Based on the Kachkanar MPP, let's note features in the distribution of indices similar for the plants. Over the years, since 1970-1980, the number of drilling rigs available at enterprises has decreased by a factor of 1.5-2. At the same time, the factor of their use increased from 0.5 to 0.8 . The length of the drilled wells for the year in the 1991-1998 time interval has sharply decreased, and then it has risen slowly to recovery and some advance of the previous indices for the 1980s.

The average number of drilling rigs does not give a complete picture of their impact on drilling results since the factor of their use for the calendar time of operation of the enterprise changes significantly. Then the presence of only working rigs, expressing their conditional quantity by the product of $n K$ should be taken into account. For example, with the list structure of 20 rigs and the factor of their use equal to 0.7 it is conventionally believed that during the annual working hours, drilling of wells has been performed by 14 rigs. In view of this, the efficiency of the use of rigs is best characterized by the ratio $L / n K$, which is the specific length of the drilled wells per year by a single rig with a conditionally full time of its operation.

A typical distribution of drilling parameters based on the example of Kachkanar MPP is shown in Fig.1. Here during the observed time interval, the drilling rig fleet was reduced with a relevant increase in the factor of their utilization, and the specific annual length of the wells drilled by one working rig after 2000 has only increased. 
$a$



$b$

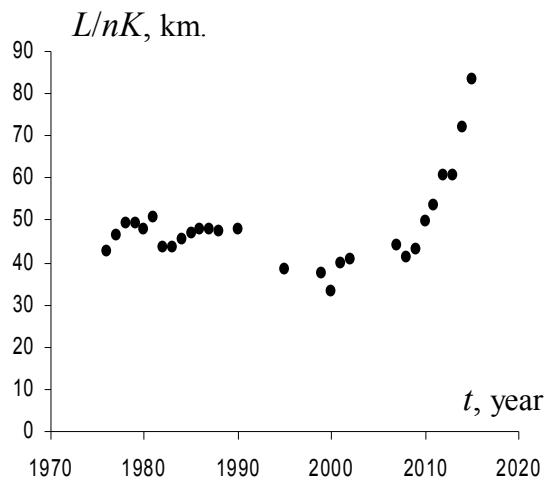

Fig. 1. The calendar distribution of the utilization rate of drilling rigs at the Kachkanar MPP by their number (a) and the specific length of the drilled wells by one machine with the conditionally full time of its operation (b).

The discrete distribution of the length $L$ by the years of drilling and the number of working machines $n K$ at the Kachkanar MPP is shown in Fig. 2, a. The error of the reproducibility of the fixed values $L$ is estimated at $5 \%$. It only qualitatively reflects the calendar change in the drilling operations. This is not enough to establish links and quantitative predictive assessments of its development. Therefore, to achieve this goal, this distribution has been studied by the experimental regression modelling.

\section{Modelling the distribution of the length of drilled wells}

The distribution of the annual length of the drilled wells $L$ in the space of a changing calendar time $t$ and the number of working drilling rigs $n K$ has been modelled by the method of non-linear functional factorial regression [12-13]. Preliminary, taking into account the root-mean-square error of the $L$ discrete values at the Kachkanar $M P P \sigma_{K}=43$ $\mathrm{km}$, the lower $R_{1}^{2}=0.85$ and the upper $R_{\mathrm{u}}^{2}=0.94$ allowable interval of the determination coefficient of the sought model have been calculated with a confidence probability of 0.95 .

The general view of the model is formed from the phenomena of the experimental distribution of the length $L$ in the $t$ coordinates, $n K$. It is noted that the monotonous and long-term change in mining production, caused by the balanced development of georesources, develops exponentially over time. The factor of depression and subsequent recovery of drilling operations, limited in time and associated with market restructuring, is expressed by an asymmetric quasi-Gaussian function. The influence of the number of working rigs $n K$ on the length of the drilled wells is described by the power function. According to the previous section, it has been taken into account that its index can vary linearly over time. Summarizing the effects of the above factors, we represent the model in the following generalized form 


$$
L=A_{1} \mathrm{e}^{\frac{\mathrm{t}}{\tau}}+A_{2} \mathrm{e}^{-\left[\frac{\left(\mathrm{t}-\mathrm{t}_{\mathrm{o}}\right)\left(1+\mathrm{e}^{\frac{\mathrm{t}-\mathrm{t}_{\mathrm{o}}}{\varepsilon}}\right)}{\tau_{1}+\tau_{2} \mathrm{e}^{\frac{\mathrm{t}-\mathrm{t}_{\mathrm{o}}}{\varepsilon}}}\right]^{2}}+A_{3}(\mathrm{nK})^{\mathrm{a}(\mathrm{t}-1975)+\mathrm{b}}+B
$$

where: $\tau$ - time relaxation of long-term changes in drilling production; $t_{0}, \tau_{1}, \tau_{2}$ - the time of the greatest decline in production, the steepness of its decline and, accordingly, the rise in the depression period; $\varepsilon$ - time parameter of transition from recession to recovery; a, bdegree parameters.

In this expression, the optimal coefficients $A_{1}, A_{2}, A_{3}, B$ have been calculated by the method of least squares, and the functional parameters by the parabolic vertex approximation method using the M3T $(\tau)$, M9T $\left(t_{0}, \tau_{1}, \tau_{2}, \varepsilon\right)$, M5T $(a, b)$ [14]. The model for the distribution of the annual length of the drilled wells at the Kachkanar MPP, obtained after optimization in the confidence interval of its mean square error of $44.5 \mathrm{~km}$, is presented in a specific mathematical form

$$
\begin{aligned}
L= & -2,35 \cdot 10^{34} e^{-\frac{t}{27}}-463,4 e^{-\left[\frac{(t-1998)\left(1+e^{\frac{t-1998}{4,1}}\right)}{3,5+11,3 e^{\frac{t-1998}{4,1}}}\right]^{2}}+ \\
& +1,4384 \cdot 10^{-29}(n K)^{23,58-0,03(t-1975)}+1199 \pm 44,5
\end{aligned}
$$

A graphic view of the model is shown in Fig. $2 b$.



Fig. 2. The distribution of the length of the drilled wells by the time of mining and the number of machines used, reflected in the annual reports (a) and the regression model (b).

Due to the fact that during the time the number of working drilling rigs changed gradually, model changes in the annual length of the drilled wells are shown in the limited intervals of changes in the $n K$ argument corresponding to the actual availability of drilling rigs at the enterprise. The model determination factor 0.90 respectively, enters the allowable range, and the deviations of the regressions from the $L i$ discrete values have the properties of normal distribution and homoscedasticity. Thus, the presented model reflects the distribution of the annual length of the drilled wells at the MPP, adequately to the error of discrete values in the initial data, that is, they are statistically reliable, and in the indicated confidence interval they express regularities in its changes. 


\section{Results and discussion}

In the model, the time parameters of changes in the annual length of the drilled wells have been determined identically, due to the long-term development of natural iron ore resources and the depressive influence of transitional economic processes. The annual length of the drilled wells, taking into account the initial design decisions for the development of natural resources, has been increasing exponentially with a relaxation interval $\tau=27$ years. The time-limited depression in drilling operations, starting from their relatively stable state in 1990 to the date of minimum $t_{\mathrm{o}}=1998$, occurs along the left slope of the right-sided asymmetric function with a steepness index of $\tau_{1}=3.5$ years. The subsequent increase in drilling operations then follows the right slope of this function with a steepness index $\tau_{2}=11.3$ years. According to the transitional parameter $\varepsilon=4.1$ years it has been determined that starting from 2005, the slope of the rising rate passes with a difference of no more than $10 \%$ in the relaxation interval of the above function.

The length of wells drilled per year increases with the number of working drilling rigs $n K$ in terms of the exponential function. Its exponent at the Kachkanar MPP is determined by the indexes $a=-0.03, b=23.58$, which are in linear dependence of the time. In 1988-1991, when the number of drilling rigs varied from 18 to 22 , the exponent was 23.1, and in 2015, with 13 working rigs, this index has a reduced value of 22.4.

The decrease in the index of working rigs $n K$ in the iron ore quarry recently, despite the growth of the $K$ factor, occurs due to a significant reduction and qualitative change in the fleet of the existing drilling rigs. In this case, the length of wells drilled per year increases, that is, drilling productivity increases. The given regularities in the distribution of the annual length of the drilled wells are explained by the structural and qualitative changes in the fleet of drilling rigs and the improvement in the organization of operation thereof. Thus, as a result of the modernization of the drilling rigs SBSh-250MNA-32 [15-16], carried out by the "Rudgormash", OJSC manufacturing plant for the last 15 years, drilling productivity has increased by 15-20\%. In addition, new high-performance SBSH 250/270-60 KP frameplatform drilling rigs have recently been used at enterprises. The organization of their repair improved and reliability of operation increased [17]. After 2000, an investment program for the replacement of a drilling rigs fleet started to be implemented at the MPP. Along with improved domestic samples, foreign are rigs are purchased, for example, American D75KS and SKS, which have higher drilling productivity [18]. As a result of modernization, modern domestic and imported rigs of various improved types are used at Kachkanar MPP [19-22].

Currently, the period of depression in the drilling operations is coming to an end. The effect of the depressive function in these models becomes very small. The annual length of the drilled wells is largely determined by the volume of mining operations, balanced by natural resources and the needs of the metallurgical complex. Obviously, in the long term, the annual drilling length at the Kachkanar MPP is approximately $L=1.200 \mathrm{~km}(B=1.199$ $\mathrm{km})$.

\section{Conclusions}

The research revealed the quantitative pattern of formation and development of drilling operations in the iron ore quarries has been revealed using the example of a large mining enterprise (Kachkanar MPP) in the transition period of the modern economy. The reliability of the created model describing the change in the annual length of the drilled wells is marked by a high index of their determination of 0.9 . The set of characteristic parameters of the complex development of drilling operations determined by the model shows the high cognitive efficiency of the method of nonlinear functional factor regression used in the 
studies. The noted regularity allowed to give an interpretation of the dynamics of drilling operations in the transition period and to evaluate their development in the short term.

The research has been carried out within the framework of the Government Task 00700293-18-00. Topic No.0405-2018-0015, and also with additional attraction of economic and contractual means and financing under the competitive project No.0405-2018-0001. Project No.18-5-5-10.

\section{References}

1. V.L. Iakovlev, A.I. Kuklin, A.I. Pavlov, Mining information-analytical bulletin, 2, 105. (2004)

2. L. F. Riehs, C. L. Henrique, R. D. Pacheco, L. F. Sartori Piran, Resources Policy, 52, 427 (2017)

3. M. Rosienkiewicz, E. Chlebus, J. Detyna, Applied Mathematical Modelling, 49, 87 (2017)

4. N. Bilim, A. Çelik, B. Kekeç, Journal of African Earth Sciences, 134, 564 (2017)

5. W.A. Hustrulid, AIME, Ch. 18 Drill Evaluation by R.H. Heinen, (1979)

6. M.A Sayed, Bulletin of the faculty of Engineering, Assiut University, 29, 255 (2001)

7. M. M. Elbeblawi, M. A. Sayed, M. T. Mohamed, E. I. Abdelrasoul, Journal of engineering sciences, 42, 557 (2014)

8. T. B. Afeni, Mining Science and Technology, 19, 73 (2009)

9. K. Žarko, Č. Miodrag, T. Dražena. Rudarski fakultet Prijedor, 9, 35 (2013)

10. V. Krúpa, M. Kruláková, E. Lazarová, M. Labaš, K. Feriančiková, L. Ivaničová, Measurement, 117, 165 (2018)

11. Technical and economic indices of mining enterprises over 1990-2012, 361 (2013)

12. V.A. Antonov, Mining information-analytical bulletin, 10, 17 (2017)

13. V.A. Antonov, Mining information-analytical bulletin, 23, 90 (2017)

14. V.A. Antonov, Izvestiia of SFedU. Technical sciences, 7 (192), 133 (2017)

15. A.V. Tokarenko, E.V. Gudenkov, Mining magazine, 3, 76 (2013)

16. V.V. Zenin, Ugol, 10 (978), 50 (2007)

17. V.D. Butkin, A.V. Gilev, Selection and rational operation of drilling tools and rigs in quarries, 236 (2010).

18. Iu.I. Lel, Mining information-analytical bulletin, 6, 199 (2011)

19. S.P. Reshetniak, Mining industry, 5(87), 18 (2009)

20. Iu. S, Alfereve, D.V. Kiselev, Iu.A. Klimashevskii, E.V. Dokukin, Mining magazine, 5, 23 (2017)

21. R.I. Sukhov, A.S. Regotunov, Kazakhstan Mining magazine, 10, 10 (2013)

22. R.I. Sukhov, V.S. Bolkisev, A.S. Regotunov, Mining equipment and electromechanics, 5, 46 (2014) 